\title{
PEDAGOGIA CRÍTICA E EDUCAÇÃO FÍSICA: uma leitura com Axel Honneth
}

Felipe Quintão Almeida'

\section{RESUMO}

Trata de uma investigação teórica que problematiza os contornos de uma pedagogia crítica na atualidade. Adota a perspectiva do filósofo Axel Honneth como fio condutor da análise, especificamente os textos em que ele discute as características contemporâneas de uma teoria adjetivada de crítica. Após descrever seu posicionamento, extrai alguns sentidos para o empreendimento crítico no âmbito de uma pedagogia da educação física.

Palavras-chave: Pedagogia Crítica. Axel Honneth. Educação Física.

1 Doutor em Educação. Professor da Universidade Federal do Espírito Santo (UFES). Vitória/Espírito Santo, Brasil. E-mail: fqalmeida@hotmail.com 
CRITICAL PEDAGOGY AND PHYSICAL EDUCATION: a review with Axel Honneth

\begin{abstract}
This paper presents a theoretical research problematizing the outlines of a critical pedagogy nowadays. It adopts the perspective of the philosopher Axel Honneth as the guiding thread of analysis, specifically the texts in which he discusses the contemporary features of a theory characterized as critical. After describing his positioning, the study draws some meanings for a critical approach within a pedagogy of physical education.
\end{abstract}

Keywords: Critical Pedagogy. Axel Honneth. Physical Education.

\title{
PEDAGOGÍA CRÍTICA Y EDUCACIÓN FÍSICA: una lectura con Axel Honneth
}

\section{RESUMEN}

Trata de una investigación teórica que problematiza las características de una pedagogía crítica en la actualidad. Adopta la perspectiva del filósofo Axel Honneth como hilo conductor del análisis, especialmente los textos en que discute las características contemporáneas de una teoria denominada crítica. Después de describir su perspectiva, busca algunos sentidos para el empreendimento crítico en el ámbito de una pedagogia de la educación física.

Palabras clave: Pedagogía Crítica. Axel Honneth. Educación Física. 


\section{INTRODUÇÃO}

Este artigo dá continuidade a outros que, em comum, tiveram como objeto de reflexão a tradição crítica da educação física brasileira e suas implicações para uma pedagogia assim adjetivada (ALMEIDA, 2006; BRACHT; ALMEIDA, 2006; BRACHT; ALMEIDA, 2008; BRACHT; GOMES; ALMEIDA, 2014; ALMEIDA; BRACHT; VAZ, 2015). Em cada um deles, discutimos a tradição à luz de teorias distintas. Continuamos aqui esse exercício, mas, desta vez, assumimos como interlocutor os textos de um filósofo ainda pouco estudado no campo acadêmico da educação física nacional. Estamos nos referindo ao alemão Axel Honneth, cujos escritos estão inseridos, conforme sua própria avaliação, no âmbito do círculo que ficou mundialmente conhecido como Escola de Frankfurt. Em seu exercício de atualização dessa teoria, quis evitar tanto o caminho oferecido pelo pós-estruturalismo francês como o daquelas perspectivas de procedimento "meramente hermenêutico" que prescindiram da possibilidade de uma crítica com teor normativo. Ao mesmo tempo, quis fazer uma indagação crítica das sociedades liberal-democráticas sem recorrer a uma filosofia da história ou, então, a uma noção "forte" ou "legisladora" de crítica social (HONNETH, 2009b, 2011b).

Nossa exposição, além de pressupor uma visão mais geral sobre a teoria de Honneth, fundamenta-se nos textos em que ele analisou, especificamente, as tarefas da Teoria Crítica pressupondo os desenvolvimentos políticos e epistemológicos das últimas décadas do século XX. Tais artigos são publicados em épocas distintas e revelam, numa leitura atenta, pontuais reformulações que o autor praticou em relação ao próprio trabalho. Um desses textos foi publicado nos anos 1980 (HONNETH, 1999), dois nos anos 1990 (HONNETH, 2011a, 2011b) e os outros dois na década seguinte (HONNETH, 2009a, 2009b). Em alguns momentos, mas não em todos, esses artigos retomam interpretações desenvolvidas no livro "Crítica do Poder", cuja primeira edição, incompleta, é de $1985 .{ }^{2}$

Em termos organizacionais, apresentamos (I) sua própria leitura da Tradição Crítica e seus "déficits sociológicos", em especial aqueles que Honneth endereça a um dos seus mais preeminentes representantes: Jurgen Habermas. Também situamos a atualização da Teoria Crítica proposta por Honneth para, ao final (II), extrairmos implicações de seus escritos para uma pedagogia crítica da educação física brasileira.

Iniciemos com um importante esclarecimento: quando Honneth se refere à Teoria Crítica, ele tem em mente uma tradição bastante específica, que remonta ao hegelianismo de esquerda, mas que desemboca numa variante ocidental do marxismo cujo texto seminal é "Teoria Tradicional e Teoria Crítica", escrito por Marx Horkheimer ainda nos anos

2 Em 1989 é publicada nova edição, acrescida de outros capítulos. 
1930, e que chega à sua máxima expressão com a publicação, em 1947, de "Dialética do Esclarecimento", assinada por Horkheimer em parceria com Theodor Adorno. Ele tem clareza de que a atualização desse modelo clássico só pode ser feita com muitas ressalvas, pois várias teses frankfurtianas adquiriram um ar antiquado e "[...] polvoriento, el aire de lo irremediablemente perdido, para lo que ya no parece haber cajá de resonância alguna en el ámbito de experiência de un presente cada vez más veloz" (HONNETH, 2009a, p. 27). O mundo contemporâneo, portanto, é inóspito para o tipo "forte" de crítica pressuposto na chamada primeira geração da Escola de Frankfurt, de maneira que apenas uma forma de crítica da sociedade que se apoie em critérios mais "débeis" constitui uma defesa legítima desde o ponto de vista político e filosófico (HONNETH, 2009b, 2011b). Para o filósofo alemão (1999), somente com a consciência desse descompasso, ou seja, apenas com a consciência de suas deficiências, é que se pode dar uma continuidade produtiva à tradição teórica inaugurada por Horkheimer.

Em sua "reconstrução", Honneth (1999, 2011a) identifica na Teoria Crítica clássica, cujo núcleo "duro" girava em torno de Horkheimer, Adorno e Marcuse, pelo menos dois grandes déficits sociológicos. Por um lado, ela pressupunha, nos anos 1930, uma filosofia da história segundo a qual o desenvolvimento das forças produtivas (o trabalho social) é considerado elemento fundante do progresso societário. Na década seguinte, mesmo que relativizando essa teoria marxista da história e sob a influência totalitária do nacional-socialismo, ainda predomina um tipo de filosofia que reduz o processo histórico a uma dimensão de dominação sobre a natureza por uma racionalidade instrumental que a tudo e a todos captura. Essa seria a marca de "Dialética do Esclarecimento". Nessa "altura", entretanto, o trabalho social já não conteria mais em si a possibilidade de uma prática emancipatória, mas representaria, ele próprio, o germe de um pensamento objetivador. Como consequência dessas premissas histórico-filosóficas, por outro lado, a Teoria Crítica da Escola de Frankfurt produziu uma análise da sociedade baseada em esquemas abstratos e universalizantes marcados por um funcionalismo que não deixou espaço para a ação social ou, para usar o linguajar de Honneth (2003), para a deflagração da gramática moral dos conflitos sociais. Segundo suas próprias palavras (2011a, p. 129-130),

[...] Horkheimer y su círculo quedaron ligados, en conjunto, a un funcionalismo marxista que les inducía a suponer un curso circular tan cerrado de dominio capitalista y de manipulación cultural dentro de la realidade social, que ya no quedaba espacio en ella para una zona de crítica práctico-moral.

Foi com Habermas, na leitura de Honneth, que a Teoria Crítica teve uma inflexão em seu programa, com implicações diversas na direção de tentar superar os dois déficits antes apontados. A crítica da Habermas aos pais fundadores da Teoria Crítica é relativamente conhecida. Em síntese, ela possibilitou a passagem de uma filosofia centrada no sujeito a uma filosofia da linguagem; como consequência, levou ao abandono do paradigma produtivista (baseado no trabalho social) em favor do comunicativo. Com esse procedimento, eis a interpretação de Honneth (1999, 2009, 2011a): o entendimento livre de qualquer 
coerção se transforma no elemento norteador das interações sociais, o que permite, por sua vez, uma apreensão mais adequada do domínio do social do que aquela oferecida pelos antecessores de Habermas (HONNETH, 1999, 2011a).

Para Honneth, portanto, qualquer tentativa de atualizar a Teoria Crítica da sociedade não deveria dar um passo aquém de Habermas e da virada que realizou. Por mais de uma vez, ele (2009a, 2011b, 2011c) anuncia isso como um fato e afirma, com seus escritos, seguir a senda inaugurada por seu colega alemão. A despeito desse reconhecimento, Honneth colocará em relevo o que considera ser alguns déficits da filosofia habermasiana, oportunidade para ele próprio desenvolver sua teoria e, então, se diferenciar de Habermas. Suas ponderações podem ser assim resumidas.

Honneth $(1999,2011 a)$ vê como problemático o dualismo habermasiano entre um mundo da vida e um mundo do sistema. Com a tese de que o primeiro é colonizado pelo segundo, ele avalia que Habermas cedeu demasiadamente às "teorias do sistema", colocando em risco o potencial real de sua abordagem teórico-comunicativa. A força dos poderes sistêmicos tornados independentes levaria, portanto, à dissolução daquele núcleo particularmente "social" da sociedade, exatamente o que estava ausente no funcionalismo da primeira geração da Escola de Frankfurt. Para Honneth, Habermas não levou até o fim a revolução teórica iniciada por ele mesmo, sendo insuficiente para reconquistar para o "social" a primazia que deveria lhe caber numa Teoria Crítica (NOBRE, 2003; RURION, 2013). A análise de Bressiani (2013, p. 264-265) é esclarecedora:

\begin{abstract}
Segundo Honneth, ao distinguir duas esferas sociais e afirmar que uma delas é funcionalmente coordenada e não depende das intenções dos atores sociais, Habermas teria criado um abismo intransponível entre ambas e diagnosticado erroneamente a impossibilidade de que as próprias lutas sociais, das quais depende o desenvolvimento histórico como um todo, pudessem alterar o funcionamento da economia e da burocracia estatal. Além disso, ao partir de uma teoria social dualista e afirmar que parte da sociedade é funcionalmente coordenada e que as relações de dominação são causadas pela interferência do sistema no mundo da vida, Habermas acabaria assumindo uma teoria do poder muito semelhante àquela defendida por Adorno e Horkheimer em A Dialética do Esclarecimento: as estruturas de poder seriam impostas sobre os indivíduos por estruturas sistêmicas que escapam inteiramente de seu controle.
\end{abstract}

Nessa analítica, as patologias sociais corresponderiam às distorções da racionalidade comunicativa causadas, no mundo da vida, pelas interferências dos imperativos funcionais do sistema. Elas pressupõem, de igual modo, o desvio de um ideal que precisa ser suposto categorialmente como critério de uma forma sã ou intacta da sociedade ou da racionalidade humana que produz "[...] un estrechamiento teórico-racional del diagnóstico crítico de la época; por que todas aquellas patologias que no concieren al plano del desarrollo de la racionalidade humana, ya no se puede ser nunca puestas a la vista" (HONNETH, 2011a, p. 139). Honneth (2011a) chega inclusive a dizer que essa característica da teoria de Habermas, que é compartilhada pelos outros membros da Escola de Frankfurt, o aproxima de uma crítica social pessimista e reintroduziria, pelas portas do fundo, uma teoria da história (NOBRE, 2013). 
A questão do conflito social e das lutas é outro tema da crítica de Honneth a Habermas. Na análise daquele, essas dimensões não foram devidamente consideradas na filosofia de seu colega. Por um lado, pois ele não foi capaz de pensar o sistema e sua racionalidade como resultado de permanentes conflitos. Por outro, a própria ideia de racionalidade comunicativa foi pensada como prévia ao conflito, como se resultasse da observância às regras que levariam a uma comunicação não distorcida. Prescindiu, assim, da possibilidade de a própria intersubjetividade comunicativa ser estruturada na luta mediada pelo conflito social.

O horizonte que será aberto por Honneth colocará em xeque a busca do entendimento racional como telos da ação comunicativa e da interação social, pois, para ele, é a suposição de um reconhecimento social que os sujeitos vinculam às suas expectativas normativas com o estabelecimento de relações comunicativas. Conforme esclarece Nobre (2003, p. 17), Honneth defende, contrariamente a Habermas, "[...] a tese de que a base da interação é o conflito, e sua gramática, a luta por reconhecimento". Honneth (2011a) não quer que sua teoria da intersubjetividade se apoie, tão somente, numa teoria da linguagem, mas postula que o paradigma da comunicação deve ser compreendido nos termos de uma teoria do reconhecimento. Nesse contexto, a perspectiva crítica do diagnóstico contemporâneo não deve estar baseada na distinção entre os mundos da vida e do sistema, mas, sim, nas causas sociais que são responsáveis pela violação sistemática das condições de reconhecimento, que passa a ser a condição normativa de toda ação comunicativa. É a luta por reconhecimento, portanto, que se transforma no paradigma da ação social. A motivação para o comportamento de protesto social e as lutas que desencadeia se baseiam na experiência "[...] de la violación de ideas de justicia dadas intuitivamente; y el núcleo normativo de estas ideas de justicia consiste una y outra vez en expectativas relacionadas con el respecto hacia la propia dignidade, el honor o la integridade" (HONNETH, 2011a, p. 137).

Tão logo uma Teoria Crítica, fundamentada no paradigma da comunicação, seja desenvolvida na direção de uma teoria intersubjetiva do reconhecimento, então o diagnóstico crítico de uma época não deve ser

[...] ya comprimido en el esquema estrecho de una teoria de la racionalidade; por que como critério de lo que tiene que ser considerado como 'transtorno' o desarrollo deficiente de la vida social, ya no se puede recurrir a las condiciones racionales del entendimento libre de domínio, sino que se tiene que recurrir a las condiciones intersubjetivas del desarrollo humano de la identidade en conjunto. Tales condiciones se encuentran en las formas sociales de comunicación en las que se cria el individuo, llega a una identidade social y finalmente tiene que aprender a concebirse como membro de una sociedade con los mismos derechos y a la vez único; si estas formas de comunicación están hechas para la superación de las diferentes tareas identitárias, entonces ello tiene que ser considerado como un indicador de desarrollo deficiente. Por lo tanto, son patologias del reconocimiento las que se convierten en el centro del diagnóstico contemporâneo, en cuanto que el paradigma de la comunicación ya no se entende en términos de la teoria linguística sino en términos de teoria del reconocimiento; en consequência, las nociones 


\begin{abstract}
básicas de un análisis social tienen que ser organizadas de tal forma que sean capaces de compreender distorciones o defectos en la estrutura social del reconocimiento, mientras que el processo de la racionalización social pierde su posición central [...]. Si el modelo de una Teoría Crítica, bosquejado hasta ahora, debe estar en condiciones de realizar algo más que un análisis meramente normativo de la actualidad, tiene que mostrar sobre todo las causas socioestructurales responsables de la distorsión en la estrutura social del reconocimiento; solo entonces se puede decidir si entre determinadas experiências de desprecio y el desarrollo estructural de la sociedade existe en realidad una relación sistemática (HONNETH, 2011a, p. 140-141).
\end{abstract}

A citação, apesar de longa, é importante, pois sintetiza traços distintivos da pretensão honnethiana de estar com, mas, também, contra Habermas em sua atualização da Teoria Crítica. Seu rechaço em relação à necessidade de uma teoria da racionalidade para fundamentar normativamente as lutas por reconhecimento pode ser lido no modo como vai deliberar sobre as funções do que chama de uma "crítica iluminadora" (HONNETH, 2011a, 2011b) que dê conta de evidenciar as patologias sociais do reconhecimento. De acordo com Honneth (2011b), uma "crítica iluminadora" da sociedade, na medida em que objetiva modificar nossas convicções axiológicas graças ao anúncio de novos pontos de vista, não deve utilizar um vocabulário de fundamentação racional. Mais bem,

[...] solo será capaz de alcanzar su efecto si emplea médios linguístico que, mediante la condensación o el desplazamiento de significados, permitan que emerjan en la realidade social hechos no percebidos hasta entonces. A las figuras retóricas que contienen semejante efecto de una apertura de nuevas conexiones de significado pertenecen tanto la exposición narrativa como la formación de metáfora sugerentes; en ambos casos se há intentado abrir un horizonte de sentido mediante la concentración precisa en determinadas asociaciones de referencias, que hacen que aparezca bajo una luz transformada el plexo integral de nuestras atividades (HONNETH, 2011b, p. 158).

Outra característica dessa "crítica iluminadora" é que ela apenas mantém uma relação indireta com a verdade possível dos pontos de vistas evocados por ela. Se a função dessa crítica é nos fazer ver o mundo a partir de outros ângulos, modificando, assim, nosso ponto de vista moral, não se deve, conforme Honneth (2011b, p. 160), construir diretamente uma pretensão de verdade para seus enunciados transmitidos retoricamente. As parábolas, metáforas ou narrações,

[...] con las cuales deben ser abiertas nuevas conexiones relevantes, solo podrían ser subitamente verdadeiros o correctos si dispusieran su efecto según el modelo de la persuasión retórica, pero no según el de la convicción argumentativa. Por ello parece más adecuado concebir una crítica de la sociedade alumbrante como el intento encapuzado a modificar las precondicioens bajo las que tienen lugar en una sociedade discursos evaluativos sobre las metas de la acción común: mediante los medios teóricos de la condensación o el desplazamiento deben ser visibles nuveos hechos en la realidade social, sobre cuya 'verdad', en efecto, solo se podrán poner de acuerdo los destinatários, después que ellos hayan examinado sus consecuêncuas 
para la direción de desarrollo de la sociedade a la luz de convicciones axiológicas concurrentes.

Não deixa de ser curioso, após apontar os "déficits sociológicos" da "primeira geração" de Frankfurt e o caráter "forte" de sua crítica social, ver Honneth (2011b) argumentar, neste texto, que a 'Dialética do Esclarecimento" reúne essas duas caraterísticas de uma "crítica iluminadora" da sociedade; afinal, ela não propõe outra interpretação da história da humanidade ou outra visão de uma "vida boa", mas provoca nos leitores uma percepção modificada da cultura capitalista que se tornou tão familiar, mediante a qual fixamos a atenção em seu caráter patológico. Também é digno de nota, no texto em tela (HONNETH, 2011b), a ausência das considerações habermasianas na definição desse tipo de "crítica iluminadora". Aliás, as duas características atribuídas por Honneth (2011b) a essa crítica contrariam argumentos que são comuns ao arcabouço habermasiano (a necessidade de uma fundamentação racional e de não prescindir de uma verdade com pretensões universais e entendida procedimentalmente).

Até o momento, vimos que Honneth (1999, 2011a) dialogou com Habermas na perspectiva de destacar seus "acertos" e os déficits de sua filosofia para, ao mesmo tempo, introduzir as marcas de sua teoria do reconhecimento, cuja obra principal tinha sido lançada por ele em 1992 (HONNETH, 2003). ${ }^{3}$ Além disso, quando Honneth (2011b) avançou em sua descrição de uma "crítica iluminadora" da sociedade, Habermas nem sequer foi mencionado. Uma consequência, talvez, da tentativa de descolar sua análise de uma teoria da racionalidade, marca importante da perspectiva habermasiana, mas também da própria tradição da Teoria Crítica. Sete anos após escrever o primeiro dos artigos aqui referenciados (HONNETH, 2011a), portanto, em 2001, Honneth (2011c) concede uma entrevista em que afirma não ver mais tanta vantagem em desvincular sua teoria do reconhecimento de uma teoria da racionalidade. Embora seja um percurso muito difícil, continua ele (2011c), entende que pode fazê-lo e que só poderia avançar com o seu próprio programa se desenvolvesse uma formulação do reconhecimento que permitisse ocupar o núcleo de uma teoria da racionalidade. ${ }^{4} \mathrm{~A}$ ideia central

[...] consistiria em notar que entendemos como a forma nuclear da racionalidade humana a segunda natureza de nossas relações de reconhecimento recíproco - em suma, a carência por reconhecimento recíproco no mundo da vida que se tornou capital para todos nós. Esse seria o núcleo de uma racionalidade que foi cada vez mais desfigurada, encoberta e substituída pelas atitudes cientificistas e instrumentais (HONNETH, 2011c, p. 151).

3 Portanto, veio a público antes dos dois textos com os quais aqui dialogamos (2011a, 2011b), respectivamente publicados em 1994 e 1998.

4 Uma primeira distinção que Honneth (2011c) afirma ter que fazer a esse respeito é entre reconhecimento e conhecimento, tema que é posteriormente tratado em sua atualização do conceito de reificação (HONNEHT, 2012), oportunidade para defender a precedência/primado do primeiro sobre o segundo. Embora isso tenha implicações para a Teoria Crítica, não será tratado aqui pois exige uma análise que extrapola a estratégia inicialmente assumida. 
Os objetivos desse deslocamento, embora ainda não completamente claros (BRESSIANI, 2013), impactaram a sua compreensão da "crítica iluminadora" do mundo, produzindo mudanças em relação àquilo que ele tinha defendido nos textos das décadas passadas (HONNETH, 1999, 2011a, 2011b). Esse novo projeto, anunciado na entrevista, é retomado em "Patologias da razão: história e atualidade da Teoria Crítica", publicado originalmente em 2007. Nele, há dois capítulos dedicados à Teoria Crítica; um escrito em 2000 (HONNETH, 2009b), antes, portanto, de conceder a entrevista mencionada; e outro publicado, pela primeira vez, em 2004 (HONNETH, 2009a).

Com a operação que realiza, Honneth dá, por assim dizer, um "passo atrás" e assume um postulado que, segundo ele, é comum a Horkheimer, Adorno, Marcuse e, mesmo, Habermas: o processo de racionalização social tem sido interrompido ou parcializado pelo desenvolvimento do capitalismo, resultando em inevitáveis patologias que acompanham a perda de um "universal racional". Todos aqueles autores partem do pressuposto de que a causa do estado patológico da sociedade é resultado de um déficit de razão social ou, o que dá no mesmo, que há um vínculo entre patologia social e falta de racionalidade. Eles "[...] ven una relación interna que explica su interés por el proceso histórico de realización de la razón. Por eso todo intento de reactivar la tradición de la Teoría Crítica para el presente debe comenzar con el intento de actualizar este acoplamento conceptual" [...] (HONNETH, 2009a, p. 31).

Não deixa de surpreender a mudança introduzida por Honneth (2009a, 2009b) na "letra" de seus escritos. Se antes, a tese de que a história humana pode ser interpretada como um processo de realização da razão estava excluída de seus textos sobre a Teoria Crítica, "[...] ahora bien, este supuesto básico, que aun hoy no es del todo absurdo [...]" (HONNETH, 2009b, p. 60), reaparece. ${ }^{5}$ Segundo nos explica Honneth (2009a, 2009b), a tese de um "universal racional" se deve, em última instância, à filosofia política de Hegel, que estava convencido de que as patologias sociais devem ser compreendidas como resultado da incapacidade de a sociedade expressar, nas instituições, nas práticas e nas rotinas cotidianas, um potencial de razão que já está latente nelas. Os distintos enfoques da Teoria Crítica sempre pressupuseram normativamente um "universal racional" que possibilita a realização plena dos sujeitos, oportunidade para lograr sua autorrealização. A autorrealização individual, nesse bojo, estaria ligada ao pressuposto de uma práxis comum que somente pode ser resultado de uma realização da razão. Honneth exemplifica que, em Habermas, esse universal racional está baseado em um conceito de entendimento comunicativo, cujas condições ideais devem garantir que, a cada etapa do desenvolvimento social, a vigência do potencial de uma razão discursiva esteja garantida. Uma patologia é desencadeada toda vez que a reprodução simbólica da sociedade não está subordinada aos estandartes de racionalidade traçados na forma mais desenvolvida do entendimento linguístico. Diferentemente do enfoque habermasiano,

5 Aliás, registre-se também que Honneth (2009) coloca em dúvida sua avaliação de que, na tradição crítica mais clássica e mesmo em Habermas, haveria uma filosofia da história. Agora, menos incisivo, ele assim se posiciona: "En ese sentido el modelo de crítica de la Escuela de Frankfurt presupone, si no precisamente una filosofia de la historia, al menos un concepto del desarrollo dirigido de la racionalidade humana" (HONNETH, 2009b, p. 61, grifo nosso). 
[...] posiblemente resulte superior un concepto que ligue más los aspectos de la racionalización social, en el sentido de un realismo interno, a la capacidade de identificar problemas que tienen las asignaciones de valor sociales; en tal caso no serían los aspectos de validez no variable del entendimento linguístico sino los critério de validez generados históricamente de las esferas de valor sociales los que marcarían la dirección en la que se produce la racionalización del saber social. También el concepto de razón com el que la Teoría Crítica intenta captar los incrementos de racionalidad en la história humana está sujeto la presión de incluir criterios ajenos e nuevos, no europeus; por eso no sorprende que también el concepto de racionalización social deba ampliarse y diferenciarse permanentemente para poder dar cuenta del caráter multiforme de los procesos sociales de aprendizaje (HONNETH, 2009a, p. 41).

Nas novas circunstâncias por ele estabelecidas, Honneth (2009a, 2009b) enfatiza o procedimento de uma crítica imanente, de acordo com a qual a crítica deve ser vista como uma forma de reflexão sobre um conceito de racionalidade que se encontra na própria realidade social. Por consequência, trata-se de reconstruir dentro da realidade social mesma as ideias ou aspirações normativas cujo caráter permitirá submeter a ordem social existente a uma crítica fundada. Para tanto, é necessário submeter o "universal racional" a uma fundamentação racional, ou seja, a uma compreensão, ela também, racional. Essa é, por assim dizer, uma particularidade fundamental da Teoria Crítica atualizada. Sem perdê-la de vista, seria necessário conectar o esclarecimento por meio da análise racional a uma explicação sociológica ${ }^{6}$ dessa deformação patológica da razão, quer dizer, uma análise explicativa dos processos que têm levado à sua danificação. Segundo as palavras de Honneth (2009a, p. 39),

[...] en la Teoría Crítica hay que complementar la crítica normativa con un elemento de explicación histórica: el haber falado en encontrar un universal racional, lo que constituye la patologia social del presente, tiene que explicarse causalmente por un processo histórico de deformación de la razón que a sua vez permita hacer entendible la destematización pública de las anomalias sociales.

Essa particularidade deve ser complementada por investigações genealógicas focadas no estudo do contexto efetivo de aplicação das normas morais, porque "[...] sin el apêndice de este examen histórico la crítica no puede tener la seguridade de que los ideales a los que há recurrido siguen teniendo en la práxis social el significado normativa que los caracterizó originalmente" (HONNETH, 2009b, p. 63).

Para Bressiani (2013), a tentativa honnethiana de vincular sua teoria do reconhecimento ao núcleo de uma teoria da racionalidade precisa atender, ainda, a outra

6 Honneth admite que sua teoria do reconhecimento (2003) também é deficitária em relação a essa particularidade da Teoria Crítica, pois seu modelo antropológico do reconhecimento, ao centrar-se nas questões psicológicomorais de motivação subjetiva, conferiu pouca atenção às explicações sociais (BRESSIANI, 2013). Ele vai tentar corrigir esse déficit na sequência do seu trabalho. 
particularidade da Teoria Crítica: evidenciar por que as pessoas, em situações de déficit da razão social, querem "completar" a razão. Nesse aspecto, Honneth precisa encontrar uma solução para um déficit motivacional que ele diz residir em toda tradição da Teoria Crítica, quer dizer, necessita elaborar um modelo que dê conta de explicar a motivação racional dos agentes sociais. Honneth entende que nem mesmo a proposta habermasiana é suficiente para explicar o motivo de as pessoas agirem, sempre, conforme a força do melhor argumento ou das melhores razões. Como, então, superar os estados de sofrimento provocados pela danificação da razão? Quais são as experiências, as práticas ou as necessidades que fazem persistir no ser humano um interesse por "completar a razão"? Qual a saída que Honneth elabora para essa necessidade? Propõe o desenvolvimento de um modelo crítico que explique a motivação moral dos agentes sociais, evidenciando, assim, a existência de um sentimento moral que leva as pessoas a lutar pela superação dos bloqueios ou patologias que impedem a emancipação. Nesse movimento, Honneth quer nos convencer de que as relações de reconhecimento são importantes para a formação das expectativas morais que os indivíduos dirigem aos seus parceiros de interação e que os impulsionam a agir. Para ser fiel à tradição que quer atualizar, as lutas por reconhecimento precisam ser concebidas como lutas racionais para a emancipação do sofrimento. Segundo avalia, esse é o caminho para um conceito mais realista de "interesse emancipador", "[...] que supone un núcleo inextirpable de capacidade de reacción racional de los sujetos a los interesses de la crítica [...]" (HONNETH, 2009a, p. 51).

Em linhas gerais, essa é a trama que Honneth desenvolveu, nos textos que escoIhemos para dialogar, ao defender uma Teoria Crítica cuja agenda esteja à altura de seu tempo. A seguir, vamos explorar suas considerações no sentido de pensar alguns traços de uma pedagogia crítica da educação física brasileira.

\section{II}

Uma pedagogia crítica na educação física brasileira não tem origem nos marcos teóricos da Escola de Frankfurt, ao menos quando considerados os "pais fundadores" dessa tradição. No campo, essa perspectiva teve seu impulso inicial devido à influência da pedagogia marxista, especialmente a adjetivada de histórico-crítica, nos intelectuais do chamado movimento renovador (ALMEIDA; BRACHT; VAZ, 2015). Só alguns anos depois de sua presença é que outras perspectivas teóricas, entre elas a dos frankfurtianos, começam a influenciar o discurso crítico na educação física, ocasião, inclusive, para colocar em xeque alguns princípios daquela tradição e argumentar sua refundação. Nesse contexto, Habermas desponta como um dos autores que teve suas ideias ecoadas na área. Seguindo a senda inaugurada por ele, mas traçando um caminho próprio, agora é a vez Honneth despontar em alguns dos escritos do campo. Não curiosamente é Bracht o autor que tem feito, tradicionalmente, a interlocução com esses dois autores da Teoria Crítica. ${ }^{7}$

7 Entre outros, consultar Bracht (1999, 2016), Bracht e Silva (2016) e Faria, Silva e Bracht (2012). 
Vemos essa presença com muitos bons olhos, pois a filosofia de Honneth, ao mesmo tempo em que nos possibilita reconstruir uma pedagogia crítica e sua agenda emancipatória, ${ }^{8}$ o faz com a consciência de seus limites. Novamente saltariam aos olhos, com ele, os "déficits sociológicos" que a área da educação física já identificou em sua produção crítica (a ênfase às macroestruturas, o economicismo das análises, a desconsideração da experiência dos sujeitos), pois também Honneth se coloca contra todo modelo crítico que atribui primazia a estruturas, funções ou a instituições sociais. Formulados nos termos de sua filosofia, o esquematismo e o funcionalismo das análises da pedagogia crítica ${ }^{9}$ resultaram numa compreensão da interação social (especialmente na escola) de modo muito estanque, deixando pouco espaço para uma zona de crítica prático-moral em suas reflexões. Em outras palavras, com Honneth, é possível tentar corrigir o déficit do "social" da pedagogia crítica em educação física, uma característica por ele criticada em relação aos membros da Escola de Frankfurt, incluindo o próprio Habermas. No horizonte de sua teoria, o "social", que corresponde às relações de reconhecimento que atravessam o mundo do trabalho e da vida docente, seria o ponto de partida de uma pedagogia crítica preocupada com essa dimensão prático-moral que, durante algum tempo, não esteve nos esforços críticos da área. Isso significa que o futuro dessa tradição precisa incorporar meios teóricos-empíricos ${ }^{10}$ que considerem essa esfera tão importante para compreender as motivações morais que levam os agentes sociais (professores) a se engajarem em práticas de autorrealização e emancipação para a superação do desrespeito ou, então, que explique a paralisia diante das causas que provocam o sofrimento e a denegação de reconhecimento na escola.

Soma-se àquele déficit outro, de caráter epistemológico, segundo o qual a pedagogia crítica foi construída a partir de um modelo "forte" de crítica, caracterizado por um discurso com aguda pretensão legisladora e descolado do contexto (BRACHT; ALMEIDA, 2008; BRACHT; GOMES; ALMEIDA, 2014; ALMEIDA; BRACHT; VAZ, 2015). Começamos a conhecer os impactos negativos da crítica assim concebida na identidade dos docentes, que se viram ameaçados pela teoria diante do novo "projeto de ordem" postulado para a disciplina. ${ }^{11}$ Como lição, aprendemos que somente uma crítica consciente dos seus alcances (neste sentido, "débil", mais "contextualizada" e "pragmatizada") é legítima para orientar qualquer atualização da pedagogia crítica. Com Honneth, podemos levar adiante esse exercício, desenvolvendo uma crítica "esclarecedora e/ou iluminadora" do cotidiano sem a pretensão de ser um "discurso extraordinário", "legislador" ou "forte", mas que, ao mesmo tempo, não prescinda de sua pretensão normativa (BRACHT, 2016). Do contrário,

8 Evitando, assim, a alternativa do "adeus à educação física progressista" (LIMA, 1997).

9 Esse esquematismo e o funcionalismo que o acompanha são denunciados de diferentes pontos de vista. Conferir, a respeito, Caparroz (2001), Oliveira (2001) e Almeida, Bracht e Vaz (2015).

10 Em Faria (2012), temos um exemplo nessa direção.

11 Machado (2012) conclui que o impacto daquele discurso legislador promoveu, entre os professores escolares de sua pesquisa, uma denegação do reconhecimento, ou seja, o não reconhecimento de suas capacidades e realizações, o que produziu situações de desrespeito que acabaram afetando a identidade docente e, consequentemente, a pessoa que é o professor. 
não seria uma pedagogia crítica. Portanto, é nas relações de reconhecimento social que uma pedagogia crítica deve se atrelar, se seguirmos Honneth, seu dever ser. O exercício, então, passa a ser a investigação das bases morais de uma intersubjetividade ancorada no reconhecimento recíproco, ou seja, nas experiências em que os sujeitos estão envolvidos para a formação de suas identidades docentes. Essa dinâmica permite visualizar como as dimensões morais confluem no processo de constituição da subjetividade docente. Se indivíduos e os grupos só podem formar suas identidades quando forem reconhecidos intersubjetivamente pelos demais nas relações sociais, nas práticas e instituições de uma dada comunidade (neste caso, a escolar), a autorrealização individual dos professores dependeria das relações bem-sucedidas de reconhecimento, graças as quais adquirem autoconfiança, autorrespeito e autoestima (HONNETH, 2003). A violação de qualquer uma dessas três esferas do reconhecimento provocaria sentimentos de desrespeito e de injustiça e caracterizaria os estados patológicos contra os quais uma pedagogia crítica deveria, normativamente, se indispor.

A centralidade do conflito na luta por reconhecimento permite, também, repensar seu lugar no seio de uma pedagogia crítica. Sua tarefa seria compreender a gramática moral do conflito que subjaz a toda interação social. Se, numa pedagogia crítica de inspiração habermasiana, conforme podemos apreender em Bracht e Almeida (2008), a busca do consenso e do entendimento livre de qualquer coerção deveria orientar os esforços normativos/ comunicativos dos envolvidos no processo educacional, com Honneth, uma pedagogia crítica entende o conflito como constitutivo da intersubjetividade comunicativa (do entendimento, portanto) e pressupõe que a interação social se constitui na luta mediada pelo conflito social. Honneth (2003) alerta, contudo, que uma teoria social de teor normativo, como é o caso de uma pedagogia crítica, depende de um conceito não utilitarista de luta que assume como ponto de partida os sentimentos morais de injustiça. Todo ato coletivo de resistência e rebelião é atribuído a um quadro invariante de experiências morais, dentro do qual a realidade é interpretada em função de uma gramática cambiante de reconhecimento e desrespeito. Trata-se, portanto, de uma luta pelas condições intersubjetivas de integridade pessoal. Quando essas pretensões são desapontadas, o envolvimento nas lutas tem a "[...] função direta de arrancá-los da situação paralisante do rebaixamento passivamente tolerado e de lhes proporcionar, por conseguinte, uma autorrelação nova e positiva" (HONNETH, 2003, p. 259). Logo, uma pedagogia crítica precisa estar atenta às motivações morais que levam os indivíduos (os professores) a desencadear o conflito e a se engajarem em lutas contra as patologias que impedem sua autorrealização. A própria luta de classes, que ainda hoje é objeto da reflexão crítica na educação física, deve ser lida como um conflito moral que resulta da destruição das condições do reconhecimento recíproco (em vez de, como na educação física, restrita às exigências que têm a ver imediatamente com a organização do trabalho social ou com as suas regras econômicas).

Uma pedagogia crítica inspirada na filosofia de Honneth mantém viva, além disso, seu interesse pelo poder emancipador e analítico da razão, contrariando algumas 
perspectivas que, deflagrada sua crise no século XX, relativizaram seu potencial de transformação por meio de uma compreensão racional dos processos sociais. Em certo sentido, as chamadas pedagogias pós-críticas e/ou pós-modernas (ALMEIDA, 2006; BRACHT; ALMEIDA, 2006) alimentaram essa descrença na razão. Uma pedagogia crítica concebida nos marcos de sua teoria mantém, ao contrário, uma poderosa fé no esclarecimento racional, pretendendo salvar um conceito não intacto (danificado, cindido) de racionalidade por meio da própria razão (salvar o conceito por meio do próprio conceito). Sua tarefa seria "iluminar" categorialmente a realidade social, de tal modo que, com essa iluminação, siga viva a possibilidade intramundana de emancipação, que deve ser entendida, ao final, nos marcos de uma teoria do reconhecimento. Para tanto, uma pedagogia crítica baseada nos seus escritos deve também pressupor relação com uma teoria da racionalidade, pois aprendemos, com o autor, que o presente patológico corresponde a déficits da razão social ou de um "universal racional" já possibilitado em termos históricos. Nessa teoria da racionalidade, o reconhecimento é seu núcleo normativo e o conflito sua mola propulsora, em vez da busca do entendimento racional em condições ideais de fala (como seria no caso de Habermas).

Há outro aspecto promissor, que derivamos da filosofia de Honneth, para a pedagogia crítica. Com ela, temos uma possibilidade de conciliar a crítica normativa da sociedade com um procedimento genealógico. Isso porque uma pedagogia crítica que leve a sério os seus ensinamentos deve tomar parte, também, de um projeto genealógico de estudar o contexto efetivo de aplicação das suas pretensões normativas. Isso é muito importante, pois nem mesmo as pedagogias críticas, com seus discursos emancipadores e libertadores, estão livres, a priori, da vontade do domínio, do controle e das relações estratégicas do poder (ALMEIDA, 2006) que podem transformar até mesmo as melhores intenções em estados de dominação. Essa preocupação genealógica possibilita saber, conforme aprendemos com Honneth, se os ideais aos quais essa pedagogia tem recorrido seguem, na prática, os significados normativos que os caracterizavam inicialmente. Na recente história da educação física brasileira, e do seu discurso crítico, essa preocupação nem sempre foi seriamente considerada.

Além dessas, poderíamos extrair outras implicações da filosofia de Honneth para pensar os contornos de uma pedagogia crítica na atualidade. Isso exigiria, por sua vez, avançar em outras direções de sua obra, o que a estratégia aqui assumida não permitiria. Um exercício interessante seria pensar na crítica da ideologia, tarefa importante da pedagogia crítica em educação física (ALMEIDA; BRACHT; VAZ, 2015), nos marcos de uma teoria do reconhecimento (ideologia como falso reconhecimento). Outro seria discutir um conceito emancipatório de trabalho no seio daquela mesma teoria. Todos esses temas com os quais Honneth se ocupou e que podem ser importantes para a renovação de uma pedagogia crítica. A esses desafios acrescentamos outro, para finalizar, que é discutir a interpretação que Honneth opera da tradição que o antecedeu e que pretende atualizar. Provavelmente nos ocuparemos desses exercícios na sequência. 


\section{REFERÊNCIAS}

ALMEIDA, F. Q. Pedagogia crítica da Educação Física no jogo das relações de poder. Movimento, Porto Alegre, v. 12, p. 141-164, 2006.

ALMEIDA, F. Q.; BRACHT, V.; VAZ, A. F. Educação física, pedagogia crítica e ideologia: gênese e interpretações. Movimento, Porto Alegre, v. 21, p. 317-331, 2015.

BRACHT, V.; ALMEIDA, F. Q. Emancipação e diferença na educação: uma leitura com Bauman. São Paulo: Autores Associados, 2006.

BRACHT, V.; ALMEIDA, F. Q. O debate Rorty/Habermas: implicações para a relação entre a teoria e a prática pedagógica na educação física. Revista Brasileira de Ciências do Esporte, v. 29, p. 123-136, 2008.

BRACHT, V.; GOMES, I. M.; ALMEIDA, F. Q. Por uma Sociologia (ainda) crítica do esporte nas Américas: o papel dos intelectuais e das associações científicas. Movimento, Porto Alegre, v. 20, p. 31-42, 2014.

BRACHT, V. Educação física escolar na América Latina. In: SILVA, P. C. C. et al. Territorialidade e diversidade regional no Brasil e na América Latina: suas conexões com a educação física e as ciências do esporte. Florianópolis: Tribo da llha, 2016. 71-97.

BRESSIANI, N. Luta por reconhecimento e diagnóstico das patologias sociais: dois momentos da teoria crítica de Axel Honneth. In: MELO, R. A teoria crítica de Axel Honneth: reconhecimento, liberdade e justiça. São Paulo: Saraiva, 2013. p. 257-292.

CAPARROZ, F. E. Entre a educação física na escola e da escola. São Paulo: Autores Associados, 2001.

FARIA, B. A. As relações de reconhecimento social na cultura escolar: um caminho para a compreensão da construção das identidades docentes. 2012. Dissertação (Mestrado em Educação Física) - Programa de Pós-Graduação em Educação Física, Universidade Federal do Espírito Santo, Vitória, 2012.

FARIA, B. A; SILVA, T. M.; BRACHT, V. A inovação e o desinvestimento pedagógico na educação física escolar. Motriz, Rio Claro, v. 18, n. 1, p. 120-129, jan./mar. 2012.

HONNETH, A. Teoria crítica. In: GIDDENS, A.; TURNER, J. Teoria social hoje. São Paulo: Editora da Unesp, 1999. p. 503-552.

. Lutas por reconhecimento: a gramática moral dos conflitos sociais. São Paulo: Editora 34, 2003.

. Una patologia social de la razón: sobre el legado intelectual de la teoría crítica. In:__. Patologías de la razón: historia y actualidad de la teoría crítica. Buenos Aires: Katz, 2009a. p. 27-51.

. Crítica reconstructiva de la sociedade con salvedad genealógica: sobre la idea de "crítica" en la Escuela de Frankfurt. In: Patologías de la razón: historia y actualidad de la teoría crítica. Buenos Aires: Katz, 2009b. p. 53-63.

. La dinâmica social del desprecio: hacia una ubicació de uma teoría crítica de la sociedad. In: HONNETH, A. La sociedade del desprecio. Madri: Trotta, 2011a. p. 127-145. 
- Sobre la posibilidad de una crítica alumbrante. La Dialéctica de la Ilustración en el horizonte de los debates actuales sobre la crítica social. In: HONNETH, A. La sociedade del desprecio. Madri: Trotta, 2011b. p. 147-163.

. A teoria crítica da Escola de Frankfurt e a teoria do reconhecimento. Cadernos de Filosofia Alemã, São Paulo, n. 18, p. 133-160, 2011c.

. Reificación: un estudio en la teoría del reconocimiento. Buenos Aires: Katz editores, 2012.

LIMA, H. L. A. Adeus à Educação Física Progressista. In: X CONGRESSO BRASILEIRO DE CIÊNCIAS DO ESPORTE, 1997, Goiânia. Anais... 1997. v. 1. p. 83-88.

MACHADO, T. S.; BRACHT, V. O impacto do movimento renovador da educação física nas identidades docentes: uma leitura a partir da "teoria do reconhecimento" de axel honneth. Movimento, Porto Alegre, v. 22, n. 3, p. 849-860, jul./set. 2016

MACHADO, T. M. Sobre o impacto do Movimento Renovador da Educação Física nas identidades docentes. 2012. Dissertação (Mestrado em Educação Física) -Programa de Pós-Graduação em Educação Física, Universidade Federal do Espírito Santo, Vitória, 2012.

MELO, R. Práxis social, reconhecimento e trabalho: o problema da reconstrução antropológica da teoria crítica. In: . A teoria crítica de Axel Honneth: reconhecimento, liberdade e justiça. São Paulo: Saraiva, 2013. p. 145-178.

NOBRE, M. Apresentação. In: HONNET, A. Lutas por reconhecimento: a gramática moral dos conflitos sociais. São Paulo: Editora 34, 2003. p. 7-19.

. Reconstrução em dois níveis. In: MELO, R. A teoria crítica de Axel Honneth: reconhecimento, liberdade e justiça. São Paulo: Saraiva, 2013. p. 11-54.

OLIVEIRA, M. A. T. A Revista Brasileira de Educação Física e Desportos (1968-1984) e a experiência de professores da rede municipal de ensino de Curitiba: entre a adesão e a resistência. 2001. 399 f. Tese (Doutorado em Educação: História e Filosofia da Educação) - Programa de Estudos Pós-Graduados em Educação, Pontifícia Universidade Católica, São Paulo, 2001.

Recebido em: fevereiro/2017

Aprovado em: abril/2017 